\title{
Diet and Genotype Effects on n-3 Polyunsaturated Fatty Acids of
}

\section{Beef Lipids}

\author{
Pilar Teresa García ${ }^{1 *}$, Nestor Latimori², Ana Maria Sancho ${ }^{1} \&$ Jorge José Casal $^{3}$ \\ ${ }^{1}$ Área Bioquímica y Nutrición, Tecnología Alimentos, Centro de Investigación en Agroindustria, CIA \\ Instituto Nacional de Tecnología Agropecuaria, INTA \\ ${ }^{2}$ Estación Experimental Agropecuaria Marcos Juárez INTA, Córdoba, Argentina \\ ${ }^{3}$ Facultad de Agronomía y Ciencias Agroalimentarias, Universidad de Morón. Buenos Aires, Argentina \\ * Pilar Teresa García, E-mail: garcia.pilar@inta.gob.ar
}

\begin{abstract}
The aim of this study was to study the effects of four feeding systems on n-3 Polyunsaturated Fatty Acids (PUFAs) in Longissimus dorsi muscle lipids from three different steer genotypes and discuss the current finding concerning the role of these factors on alfa-linolenic acid conversion into n-3 long chain PUFAs. The feeding systems described here, represent productive models widespread in Argentina Pampeana region, ranging from pasture exclusive diet, to the feedlot system. C18:2 n-6 (LA) increased whereas C18:3 n-3 (ALA) decreased according to the increase in grain in the diet. The LA/ALA and n-6/n-3 PUFAs ratios increased as the grain in the diet increased. We concluded that by feeding animals correctly, we address the problem of consuming a high n-6/n-3 PUFAs ratio without virtually changing normal diets. Although these changes appear modest, for non-sea fish eaters, animal products such as beef are the only sources of long-chain n-3 PUFAs, and any improvement in the fatty acid composition of beef will result in an increase in the consumption of $n-3$ fatty acids.
\end{abstract}

\section{Keywords}

healthy beef, linoleic acid, linolenic acid, LA/ALA ratio, n-6/n-3 PUFAs

\section{Introduction}

Studies in meat science are advancing the development of foods with characteristics that benefit human health. Both Linoleic Acid (LA) and Alpha-Linolenic Acids (ALA) belong to the n-6 (omega 6) and n-3 (omega 3) series of Polyunsaturated Fatty Acids (PUFAs) respectively. LA and ALA are defined as essential fatty acids because they are not synthesized in the human body and thus have to be obtained from the diet. Hence, it is essential to provide these two acids in the diet, because they are precursors for Long Chain Polyunsaturated Fatty Acids (LC-PUFAs) (Williams, 2000). LA, which is practically found in every food, is the most prominent PUFA in the Western diet. As LA is the metabolic precursor of Arachidonic Acid (ARA) and derived bioactive eicosanoids, there is concern that dietary LA could increase tissue ARA, eicosanoid formation and subsequently enhance the risk of and/or exacerbate 
conditions associated with acute and chronic diseases (Whelan, 2008).

According to recent studies the conversion of ALA into n-3 LC-PUFAs, especially 22:6 n-3 (DHA) in humans is scarce and is affected by the ratio LA/ALA, the total PUFAs and the amounts of ALA in the diet (Barcelo-Coblijn \& Murphy, 2009). The conversion of ALA into LC-PUFAs is decreased by high dietary ratios of LA/ALA. Moreover, n-6 fatty acids intake influences tissue concentrations of n-3 LC-PUFAs (Brenna et al. 2009). Competitive interactions among n-6 and n-3 PUFAs at the level of formation and action of eicosanoids, appear to relate directly to potential benefits attributed to an eligible dietary balance of n-3 and n-6 PUFAs. With higher dietary ratios of n-6/n-3 PUFAs, the pro-inflammatory/aggregatory eicosanoids from LA are favoured over those from ALA, showing anti-inflammatory/aggregatory effects. Controlling the synthesis of n-3 LC-PUFA, such as EPA (20:5 $\mathrm{n}-3$ ) and DHA, from ALA, as well as controlling the respective eicosanoids by consumption of the optimized ratio of $n-6$ to $n-3$ is, therefore, the particular nutritional focus of interest. Since members of the n-6 and n-3 PUFAs fatty acid families compete for the corresponding enzyme systems the conversion of LA or ALA into their longer chain homologues is significantly influenced by the composition of dietary fats. Most of the fat intake in humans comes from animal products (meat, milk, eggs, etc.). This has changed because animals used to eat mainly forages (high ALA and low LA) but now they typically eat less forage and consume more cereals and soy bean (high LA and low ALA). As a result, the animal products are now much higher in n-6 PUFAs and lower in n-3 PUFAs. Smink et al. (2013) suppressed the effect of ALA intake on n-3 LC-PUFAs by LA intake and suppressed the concentration of n-6 LC-PUFAs in blood plasma by dietary ALA. They found that the inhibiting effect of ALA in blood ARA, at equal increasing intakes, was stronger than the stimulating effect of LA as a precursor. Analysis of n-3 PUFA intake, intake recommendations, and health claims are often limited to ALA, EPA and DHA and omit Docosapentaenoic Acid (DPA). DPA is an intermediate in the production of DHA from EPA and its contribution in beef lipids is higher than that of EPA and DHA. The functional and nutritional attributes of DPA are largely unknown but some studies have shown that DPA appears to be a primary end point for the synthesis of n-3 PUFAs from ALA (Howe et al., 2006).

Data from a large number of studies regarding LA and ALA proportions in beef lipids indicate that the fatty acid composition vary largely across production systems (Garcia \& Casal, 2012). The fatty acid composition of adipose tissue and muscle in cattle is affected by several factors as diet, total fat content, breed, genotype, age and gender. Genetic variation in the fatty acid composition of adipose tissue triacylglycerols, with breed differences were observed in several studies. However, in the phospholipid fraction, the total amount of PUFAs does not differ among crossbreed groups, because certain amounts of unsaturated fatty acids are required to maintain the physical properties of the cell at the body temperature of mammals (Malau-Aduli et al., 1998). Sexton et al. (2012) showed that there is a sire breed $\mathrm{x}$ time of weaning interaction for percent total PUFA, with the Charolaise steers having a greater PUFAs percentages than other treatment groups. Humada et al. (2012) studied the effects of two production systems (semi-intensive vs. intensive), and two slaughter ages (12 vs.14 months) on LA and Published by SCHOLINK INC. 
ALA proportions on beef fatty acids composition. The slaughter age affected LA or ALA proportions. LA and ALA are strongly positively correlated to intramuscular fat of Longissimus dorsi muscle at the quantitative level (mg/100g fresh tissue), but there are negative correlation coefficients for the relative proportion of these fatty acids to intramuscular fat. The relationships between intramuscular fat and the fatty acid profile of triglycerides and phospholipids fractions are weaker compared to total muscle fat. The aim of this work was to study the effects of four feeding systems on LA, ALA, n-6 and n-3 PUFAs and in LA/ALA and n-6/n-3 PUFAs ratios in Longissimus dorsi muscle lipids from three different genotypes of steers and discuss the current finding concerning the role of these factors on ALA conversion into n-3 LC-PUFAs in humans. The feeding systems described here, represent productive models widespread in Argentina Pampeana region, ranging from pasture exclusive diet, to the feedlot system. The British purebred or their crossbreds, which are the main components of the meat consumed domestically, were represented by Abedeen Angus (AA) steers. The crossbred Charolais x Aberdeen Angus (CHAxAA) steers represents the most advisable crossbred for production of heavy steers for export markets, and Argentine Holstein (HA) steers are potentially adecuate for commercial purpose.

\section{Materials and Methods}

\subsection{Animal Management of the Animals and Their Diets}

A total of 144 Aberdeen Angus (AA), Charolais x Aberdeen Angus (CHAxAA) and Argentine Holstein (HA) steers were allotted from 5-7 months old to slaughter weight to the four following treatment:

Pasture: steers grazed on pasture exclusively (mainly alfalfa and festuca).

Cn0.7\%LW: steers fed with a similar pasture but supplemented daily with cracked corn grain $(0.7 \%$ of live weight).

Cn1\%LW: steers fed with a similar pasture but supplemented daily with cracked corn grain (1\% of live-weight).

Cn85\%: steers fed with a diet based in corn grain (85\%), alfalfa hay (8.6\%), soybean meal (8.4\%) and, minerals and vitamins (0.5\%).

The forage in Pasture, $\mathrm{Cn} 0.7 \%$ and $\mathrm{Cn} 1 \%$ treatments were provided by a mixed pasture of alfalfa (Medicago sativa) and tall fescue (Festuca arundinacea Schreb) grazed under a rotational system of six paddocks with seven days of permanency in each one.

Twelve steers for treatment were assigned and they were conventionally slaughtered in a conventional abattoir at a similar degree of finishing estimated by visual evaluation. Data from the animal performance within each breed and treatment group are presented in Tables 1 and 2. 
Table 1. Animal Data: Initial and Final Live Weights and Experimental Period (EP)

\begin{tabular}{llllllllll}
\hline & \multicolumn{3}{c}{ Initial live weight $(\mathrm{kg})$} & \multicolumn{3}{c}{ Final live weight $(\mathrm{kg})$} & \multicolumn{3}{c}{ EP (days) } \\
Genotype & AA & CHAxAA & HA & AA & CHAxAA & HO & AA & CHAxAA & HA \\
\hline $\mathrm{N}$ & 12 & 12 & 12 & 12 & 12 & 12 & 12 & 12 & 12 \\
Pasture & $190 \mathrm{a}$ & $181 \mathrm{a}$ & $195 \mathrm{a}$ & $388 \mathrm{~b}$ & $449 \mathrm{a}$ & $505 \mathrm{~b}$ & 365 & 382 & 391 \\
Cn0.7\%L & $188 \mathrm{a}$ & $171 \mathrm{a}$ & $194 \mathrm{a}$ & $408 \mathrm{a}$ & $467 \mathrm{a}$ & $512 \mathrm{ab}$ & 333 & 378 & 367 \\
W & & & & & & & & & \\
Cn1\%LW & $188 \mathrm{a}$ & $174 \mathrm{a}$ & 194a & $420 \mathrm{a}$ & $483 \mathrm{a}$ & $541 \mathrm{a}$ & 289 & 356 & 354 \\
Cn85\% & $189 \mathrm{a}$ & $168 \mathrm{a}$ & 193a & $350 \mathrm{a}$ & $399 \mathrm{~b}$ & $374 \mathrm{c}$ & 152 & 192 & 170 \\
\hline
\end{tabular}

Note. abc means within a column with different letters significantly differ $(\mathrm{p}<0.05)$.

Table 2. Experimental Animals: Growth Rate (g/d) and EAC (Estimated Average Contribution) of Grain to Total Energy Intake

\begin{tabular}{lllll}
\hline \multicolumn{5}{c}{ Growth rate $(\mathrm{g} / \mathrm{d})$} \\
\hline Genotype & AA & CHAxAA & HA & EAC \\
\hline Pasture & $546 \mathrm{c}$ & $707 \mathrm{c}$ & $800 \mathrm{~d}$ & $0 \%$ \\
Cn0.7\%LWt & $675 \mathrm{bc}$ & $787 \mathrm{c}$ & $875 \mathrm{~cd}$ & $33.6 \%$ \\
Cn1\%LW & $808 \mathrm{~b}$ & $871 \mathrm{bc}$ & $983 \mathrm{bc}$ & $44.9 \%$ \\
Cn85\% & $1055 \mathrm{a}$ & $1223 \mathrm{a}$ & $1093 \mathrm{ab}$ & $85.8 \%$ \\
\hline
\end{tabular}

Note. abcd means within a column with different letters significantly differ $(\mathrm{p}<0.05)$.

\subsection{Methods of Analysis}

After $24 \mathrm{~h}$ at $4^{\circ} \mathrm{C}, 12$ steaks, $2-25 \mathrm{~cm}$ of thickness, from Longissimus Dorsi muscles at the 11th rib were taken from each group, carefully dissected and used for chemical analysis. All samples were frozen and stored at $-20^{\circ} \mathrm{C}$ until analysis were performed. Aliquot samples of $10 \mathrm{~g}$ each, trimmed of external fat, minced carefully, dried and extracted in a Tecator apparatus using hexane as the extraction solvent according to official methods (AOAC, 1992), were used to determine total intramuscular fat (IMF). Aliquot samples of $5 \mathrm{~g}$ each were extracted using the Folch et al. method (Folch et al., 1957). Fatty Acid Methyl Esters (FAME) were prepared according to the method of Pariza et al. (2001) and measured using a Chrompack CP 900 equipment (Chrompack Inc., Middleburg, The Netherlands) fitted with a flame ionization detector. Fatty acid methyl esters were separated with a fused silica capillary column CP-Sil 88 (100m x 0.25mm i.d.) from Chrompack Inc., Middleburg, The Netherlands, with N2 as the carrier gas. The oven temperature was programmed at $70^{\circ} \mathrm{C}$ for $4 \mathrm{~min}$, increased from 70 to $170^{\circ} \mathrm{C}$ at a rate of $13^{\circ} \mathrm{C} / \mathrm{min}$ and then increases from to $170^{\circ}$ to $200^{\circ} \mathrm{C}$ at $1^{\circ} \mathrm{C} / \mathrm{min}$. Individual fatty acids were identified by comparing relative retention times with individual fatty acids standard (PUFA-2 Animal Source. Supelco). Analytic results were expressed as percentages of total fatty acids 
and mg of fatty acid contribution in 100g of fresh Longissimus Dorsi muscle.

\subsection{Statistical Analyses}

Data were subjected to analysis of variance using the GLM procedure of SAS v.9.1 statistical software package. The two factorial design were considered: breed with three levels (AA, CHAxAA and AH) and diet with four levels (Pasture, pasture $+0.7 \%$ grain, pasture $+1 \%$ grain and grain) and their interactions. Tukey's test was used for means comparison.

\section{Results}

The effects of the diet on the LA and ALA proportions, n-3 and n-6 PUFAs, IMF\%, LA/ALA and ratios n-6/n-3 PUFA are shown in Tables 3 and 4.

Table 3. Effects of Genotype and Diet, on LA, ALA, n-6 and n-3\%, and LA/ALA and n-6/n-3 Ratios in Steer Longissimus Dorsi Lipids

\begin{tabular}{lllllllll}
\hline & LA\% & ALA $\%$ & $\mathrm{n}-3 \%$ & $\mathrm{n}-6 \%$ & $\mathrm{n}-6 / \mathrm{n}-3$ & LA/ALA & IMF\% & PUFA\% \\
\hline AA & 4.10 & $0.91 \mathrm{a}$ & $2.07 \mathrm{a}$ & 5,97 & $3.84 \mathrm{~b}$ & $6.36 \mathrm{a}$ & 3.57 & 8.04 \\
CHAxAA & 4.30 & $0.93 \mathrm{a}$ & $2.03 \mathrm{ab}$ & 6.24 & $3.78 \mathrm{~b}$ & $6.72 \mathrm{a}$ & 3.80 & 8.27 \\
HA & 4.29 & $0.81 \mathrm{~b}$ & $1.82 \mathrm{~b}$ & 6.41 & $4.71 \mathrm{a}$ & $8.05 \mathrm{~b}$ & 3.59 & 8.22 \\
Pasture & $3.55 \mathrm{~b}$ & $1.38 \mathrm{a}$ & $3.09 \mathrm{a}$ & $5.48 \mathrm{~b}$ & 1.08 & $2.59 \mathrm{c}$ & $2.89 \mathrm{~b}$ & $8.57 \mathrm{ab}$ \\
Cn0.7\% & $3.76 \mathrm{~b}$ & $0.99 \mathrm{~b}$ & $2.09 \mathrm{~b}$ & $5.61 \mathrm{~b}$ & 2.69 & $3.84 \mathrm{bc}$ & $3.58 \mathrm{ab}$ & $7.70 \mathrm{~b}$ \\
Cn1.0\% & $3.94 \mathrm{~b}$ & $0.77 \mathrm{c}$ & $1.69 \mathrm{c}$ & $5.91 \mathrm{~b}$ & 3.61 & $5.31 \mathrm{~b}$ & $4.25 \mathrm{a}$ & $7.61 \mathrm{~b}$ \\
Cn85\% & $5.65 \mathrm{a}$ & $0.39 \mathrm{~d}$ & $1.01 \mathrm{~d}$ & $7.82 \mathrm{a}$ & 8.32 & $16.43 \mathrm{a}$ & $3.90 \mathrm{a}$ & $8.83 \mathrm{a}$ \\
RMSE & 0.97 & 0.20 & 0.49 & 1.40 & 1.34 & 3.59 & 1.32 & 1.76 \\
Genotype & 0.53 & 0.008 & 0.028 & 0.307 & 0.001 & 0.057 & 0.043 & 0.797 \\
Diet & 0.000 & 0.000 & 0.000 & 0.000 & 0.000 & 0.000 & 0.000 & 0.005 \\
GxD & 0.611 & 0.267 & 0.348 & 0.537 & 0.004 & 0.381 & 0.135 & 0.609 \\
\hline
\end{tabular}

Note. *Significance of main effects (breed, diet) and their interaction (G x D)

abcd means within a column with different letters significantly differ.

RMSE: Root mean square error n-3 (18:3+20:5+22:5+22:6); n-6 (18:2+18:3+20:3+20:4+22:4);

PUFA\% $\%=n-6+n-3 \%$.

IMF: Intramuscular fat 
Table 4. Effects of Genotype and Diet on n-6 and n-3 PUFAs (Percent of Total Fatty Acids) on Steer Longissimus Dorsi Muscle Lipids

\begin{tabular}{llllllll}
\hline & $18: 2 \mathrm{n}-6$ & $20.3 \mathrm{n}-6$ & $20: 4 \mathrm{n}-6$ & $18: 3 \mathrm{n}-3$ & $20: 5 \mathrm{n}-3$ & $22: 5 \mathrm{n}-3$ & $22: 6 \mathrm{n}-3$ \\
\hline AA & 4.10 & 0.44 & $1.10 \mathrm{~b}$ & $0.91 \mathrm{a}$ & 0.31 & 0.52 & 0.33 \\
CHAxAA & 4.30 & 0.42 & $1.16 \mathrm{~b}$ & $0.93 \mathrm{a}$ & 0.31 & 0.50 & 0.29 \\
HA & 4.29 & 0.44 & $1.41 \mathrm{a}$ & $0.81 \mathrm{~b}$ & 0.35 & 0.52 & 0.13 \\
Pasture & $3.55 \mathrm{~b}$ & 0.44 & 1.12 & $1.38 \mathrm{a}$ & $0.57 \mathrm{a}$ & $0.76 \mathrm{a}$ & 0.38 \\
Cn0.7\% & $3.76 \mathrm{~b}$ & 0.41 & 1.18 & $0.99 \mathrm{~b}$ & $0.34 \mathrm{~b}$ & $0.53 \mathrm{~b}$ & 0.23 \\
Cn1.0\% & $3.94 \mathrm{~b}$ & 0.42 & 1.23 & $0.77 \mathrm{c}$ & $0.35 \mathrm{~b}$ & $0.47 \mathrm{~b}$ & 0.20 \\
Cn85\% & $5.65 \mathrm{a}$ & 0.46 & 1.35 & $0.39 \mathrm{~d}$ & $0.14 \mathrm{~b}$ & $0.30 \mathrm{c}$ & 0.17 \\
RMSE & 0.97 & 0.16 & 0.48 & 0.20 & 0.13 & 0.20 & 0.13 \\
Genotype & 0.53 & 0.851 & 0.005 & 0.008 & 0.241 & 0.725 & 0.000 \\
Diet & 0.000 & 0.588 & 0.236 & 0.000 & 0.000 & 0.000 & 0.000 \\
GxD & 0.611 & 0.071 & 0.708 & 0.267 & 0.076 & 0.237 & 0.000 \\
\hline
\end{tabular}

Note.*Significance of main effects (breed, diet) and their interaction (G x D).

abcd means within a column with different letters significantly differ.

RMSE: Root mean square error

The diet significantly affected all these variables. The proportions of LA increased $(p<0.001)$ according with the increase in grain in the diet, whereas the ALA proportions decreased $(p<0.001)$. Total n-3 LC-PUFAs decreased significantly whereas total n-6 LC-PUFAs increased as the grain in the diet increased. Total LC-PUFAs were higher in Pasture and Cn85\% than in Cn07\% and Cn1\%. The LA/ALA and n-6/n-3 PUFA ratios were $(p<0.001)$ lower in pasture and supplement-fed beef than in the grain-fed beef. The LA/ALA ratio increased linearly as the grain in the diet increased. The $n-6 / n-3$ PUFAs ratio followed a similar pattern. IMF\% was significantly affected by the diet, being lower in pasture-fed beef than in the others.

The effects of the genotype on LA, ALA, n-3 and n-6 PUFAs, IMF percentages and LA/ALA and n-6/n-3 PUFA ratios are shown in Tables 3 and 4. The genotype affected ALA, n-3 LC-PUFAs, and n-6/n-3 PUFA and LA/ALA ratios. The beef lipids from HA showed $(p<0.001)$ lower ALA proportions than those from AA and CHAxAA, but no significant differences in the LA proportions. Total n-6 LC-PUFAs were similar in all genotypes whereas total n-3 LC-PUFAs were lower in HA than in AA and CHAxAA, which were similar. The LA/ALA and n-6/n-3 ratios were higher in HA than in the other two genotypes. The effects of genotype and diet on the estimated contributions (mg/100g fresh Longissimus dorsi muscle) of LA, ALA and n-3 and n-6 PUFAs are presented in Table 5. The effects of the diet on the contributions of LA, ALA, n-3 and n-6 and total PUFAs were more important than the genotype effects. 
Table 5. Estimated Contribution of Longissimus Dorsi Fatty Acids (mg/100g Fresh Tissue) According to Genotype and Diet

\begin{tabular}{lllllll}
\hline & LA & ALA & ARA & EPA & DPA & DHA \\
\hline AA & 144 & $31 \mathrm{a}$ & $37 \mathrm{c}$ & 10 & 17 & $10 \mathrm{~A}$ \\
CHAxAA & 159 & $33 \mathrm{a}$ & $41 \mathrm{~b}$ & 10 & 17 & $10 \mathrm{~A}$ \\
HA & 148 & $27 \mathrm{~b}$ & $47 \mathrm{a}$ & 11 & 17 & $5 \mathrm{~B}$ \\
Pasture & $101 \mathrm{c}$ & $40 \mathrm{a}$ & $31 \mathrm{c}$ & $16 \mathrm{a}$ & $21 \mathrm{a}$ & $11 \mathrm{~A}$ \\
Cn0.7\% & $126 \mathrm{c}$ & $34 \mathrm{~b}$ & $37 \mathrm{~b}$ & $11 \mathrm{a}$ & $18 \mathrm{~b}$ & $8 \mathrm{AB}$ \\
Cn1.0\% & $158 \mathrm{~b}$ & $32 \mathrm{~b}$ & $48 \mathrm{a}$ & $9 \mathrm{c}$ & $18 \mathrm{~b}$ & $8 \mathrm{AB}$ \\
Cn85\% & $216 \mathrm{a}$ & $15 \mathrm{c}$ & $49 \mathrm{a}$ & $6 \mathrm{c}$ & $11 \mathrm{c}$ & $6 \mathrm{~B}$ \\
RMSE & 45,9 & 11.3 & 15.1 & 4.1 & 6.3 & 5.4 \\
Genotype & 0.263 & 0.026 & 0.005 & 0.334 & 0.995 & 0.000 \\
Diet & 0.000 & 0.000 & 0.000 & 0.000 & 0.000 & 0.008 \\
GxD & 0.847 & 0.945 & 0.640 & 0.478 & 0.473 & 0.000 \\
\hline
\end{tabular}

Note. The estimated values were calculated according with the levels of intramuscular fat

*Significance of main effects (breed, diet) and their interaction (B x D)

abc means within a column with different letters significantly differ.

RMSE: Root mean square error

\section{Discussion}

It is well know that fatty acid composition of beef, and hence its nutritional value, can be manipulated by genetic and nutritional approaches although it is acknowledge that genetic factors provide smaller differences than dietary factors. In this study, as in a previous one, we found some evidence of genetic variation in LA and ALA proportions in beef lipids (Garcia et al. 2008). Nuernberg et al. (2005) found that the percentages of ALA in German Simmental and German Holstein bulls fed with grass or concentrate increased whereas the percentage of LA were only affected by breed being higher in German Simmental intramuscular fat. In contrast, Muchenje et al. (2009) found no differences due to the breed in the proportions of LA and ALA among Nguni, Bonsmara and Angus steers. Corazzin et al. (2012), found that Italian Simmental and Holstein bulls presented dietary differences in Longissimus thoracis muscle for LA in phospholipids and neutral lipids fractions.

We found significant increase in most of the individual muscle n-3 PUFAs and decrease in n-6 PUFAs in the case of the diet supplemented with grain when compared with pasture group. In our study beef PUFAs content was higher than the values reported by others (Scollan et al., 2006) LA is the primary PUFAs in both grass/forage-fed and grain-finished beef providing $60-85 \%$ of total PUFAs (Duckett et al., 2013). Usually the percentage of PUFAs in beef is increased by as much as $25 \%$ in response to grass-feeding due to the lower intramuscular total fat of most grass-fed beef. However, the total 
estimated amount of PUFAs in steaks from U.S. grass/forage-fed cattle may be up to $75 \mathrm{mg}$ lower per 100g of beef, primarily as LA (Daley et al., 2010). Only 16 to $26 \mathrm{mg}$ ALA have been reported in various lean cuts for grass/forage cattle versus 4-13 mg ALA from U.S. grain-finished beef, whereas but only traces of n-3 LC-PUFAs are noted in meat from U.S. grass/forage-fed cattle (Duckett et al., 2013).

The n-6/n-3 FA ratio in grass-fed beef is beneficially low, typically less than 3 (Howe et al., 2006). The decreased n-3/n-6 ratio in grazing beef is a consequence of increased ALA proportion and a relative constant proportion of LA in adipose tissues from steers on pasture compared with those finished with feedlot diets. Steers finished on a grain diet show a 2.5 times higher $n-6 / n-3$ PUFAs ratio than those finished on pasture (Basarab et al., 2007; Duckett et al., 2009). However, the fold of increase in the n-6/n-3 FA ratio can be higher when examined in beef muscles (Garcia et al., 2008). Similar results have been found for others with crossbreed heifers offered a control diet of grass silage and concentrate (Sarries et al., 2009). Alfaia et al. (2009) used Alentejano bulls to research the effect of four feeding systems (pasture feeding followed by 2 or 4 months of finishing on concentrate and concentrate only) on the fatty acid composition of muscle of Longissimus dorsi muscle and found no significant differences in the proportions of LA among all treatments. Conversely, they found that the meat from the bulls fed the pasture diet had the highest percentages of ALA. Varela et al. (2004) found that both a pasture finishing system and an indoor finishing system (maize, silage and concentrate) affected the intramuscular fatty acid profile of Rubia Gallega steers. They also found that intramuscular fat fatty acids of finished steers contained higher concentrations of LA but no differences in those of ALA. In addition, Alfaia et al. (2006) found differences in LA between meat from bullocks reared in a semi-intensive system and that from bullocks produced in a conventional intensive concentrate-based system. On the other hand, Faucitano et al. (2008) found that cattle fed high concentrate diets showed a significantly decreased the proportion of ALA in Longissimus dorsi muscle lipids. Lee et al. (2009) studied the effects of diets with grass or red clover silage on the proportions of LA and ALA in Longissimus dorsi muscle in dairy cull cows and found that red clover silage increased the percentages of LA and ALA. Herdman et al. (2010) studied the effects of two diets, one rich in LA and the other rich in ALA and found that both affected the fatty acid composition of the lipid classes in the IMF of German Simmental bulls. The bulls fed the ALA rich-diet had higher concentrations of ALA in phospholipids and triglycerides. Leheska et al. (2008) in an USA study for inclusion in the USDA National Database for Standard Reference compared the fatty acid composition of grass-fed beef and conventionally fed (control) beef. They concluded that the two production systems, semi-intensive vs. intensive, affected the LA and ALA concentrations.

While le contribution of ALA to cardiovascular diseases is debatable, evidence regarding the role of n-3 LC-PUFAs in the prevention of hearth diseases is convincing (FAO, 2010). Due to the importance of n-3 LC-PUFAs in cardiovascular health, intake recommendations suggest a minimum of $250 \mathrm{mg}$ EPA+DHA/day (EFSA, 2010). It has been shown that both grass/forage and grain-finished-fed beef can 
contribute n-3 LC-PUFAs to the U.S. diet, averaging between 5.33 and 2-19 mg/100 respectively, primarily as EPA+DPA (Van Elswyk \& McNeillet, 2014).

\section{Conclusions}

The genotype and animal diet, are the main factors considered in the current systems of beef production, affected the nutritional value of beef lipids. The LA and ALA proportions, and therefore the LA/ALA ratio of beef lipids were generally more healthy in grass-fed than grain-fed beef. Considering the importance of LA and ALA competition in the synthesis of LC n-3 PUFAs, and therefore in the concentrations of EPA, DPA and DHA in beef lipids, it is possible to optimize genotypes and animal diets. The dietary design will be of great importance to improve the nutritional value of beef. By feeding animals correctly, we address the problem of consuming too much n- 6 fatty acids at the expense of too little n-3 fatty acids, without virtually changing of diet. In conclusion, it is possible to manipulate the fatty acid composition of beef toward a more healthy profile. Although these changes appear modest, for non-fish eaters, animal products such as beef are the only sources of long-chain n-3 PUFAs, and any improvement in the fatty acid composition of beef will result in an increase in the consumption of n-3 fatty acids.

\section{References}

Alfaia, C. M. M., Ribeiro, V. S. S., Lourenco, M. R. A., Quaresma, M. A. G., Martins, S. I. V., Portugal, A. P. V., ... Prates, J. M. A. (2006). Fatty acid composition, conjugated linoleic acid isomers and cholesterol in beef from crossbred bullocks intensively produced and from Alentejana purebred bullocks reared according to Carnalentejana-PDO specifications. Meat Science, 72, 425-436.

Alfaia, C. P. M., Alves, S. P., Martins, S. I. V., Costa, A. S. H., Fontes, C. M. G. A., Lemos, J. P. C., ... Prates, J. A. M. (2009). Effect of the feeding system on intramuscular fatty acids and conjugated linoleic acid isomers of beef cattle, with emphasis on their nutritional value and discriminatory ability. Food Chemistry, 114, 939-946.

AOAC. (1992). Official Methods of Analysis 15th edition. (3rd.ed., pp. 19-140). International Gaithersburg, MD.

Barcelo-Coblijn, G., \& Murphy, E. J. (2009). Alpha linolenic acid and a role to longer chain n-3 fatty acids: Benefits for human health and a role in maintaining tissue n-3 fatty acid levels. Progress in Lipid Research, 48, 355-374.

Basarab, J. A., Mir, P. S., Aalhus, M., Shah, A., Baron, V. S., Okine, E. K., \& Robertson, W. M. (2007). Effect of sunflower seed supplementation on the fatty acid composition of muscle and adipose tissue of pasture-fed and feedlot finished beef. Canadian Journal of Animal Science, 87, 71-86.

Brenna, J. T., Salem, Jr N., Sinclair, A. J., \& Cunnane, S. C. (2009). Alpha linolenic acid supplementation and conversion to n-3 long-chain polyunsaturated fatty acids in humans. Prostaglandins, Leukotrienes and Essential Fatty Acids, 80, 85-91.

Published by SCHOLINK INC. 
Corazzin, M., Bovolenta, S., Sepulcri, A., \& Piasentier, E. (2012). Effect of whole linseed addition on meat production and quality of Italian Simmental and Holstein young bulls. Meat Science, 90, 99-105.

Daley, C. A., Abbott, A., Doyle, P. S., Nader, G. A., \& Larson, S. A. (2010). Review of fatty acid profiles and antioxidant content in grass-fed and grain-fed beef. Nutrition Journal, 9, 1-12.

Duckett, S. K., Neel, J. P. S., Lewis, R. M., Fontenot, J. P., \& Clapham, W. M. (2013). Effects of forage species or concentrate finishing on animal performance, carcass and meat quality. Journal of Animal Science, 91, 1454-1467.

Duckett, S. K., Pratt S. L., \& Pavan, E. (2009). Corn oil or corn grain supplementation to steers grazing endophy-free tall fescue. II. Effects on subcutaneous fatty acid content and lipogenic gene expression. Journal of Animal Science, 87, 1120-1128.

European Food Safety Panel of Dietetics Products, Nutrition and Allergies (NDA). (2010). Scientific opinion on dietary reference values for fat, including saturated fatty acids, polyunsaturated fatty acids, monounsaturated fatty acids, trans fatty acids, and cholesterol. European Food Safety Authority, 8, 1459-1507.

Faucitano, L., Chouinard, P. Y., Fortin, J. J., Mandell, I. B., Lafreniere, C., Girard, C. L., \& Berthiaume, R. (2008). Comparison of alternative beef production systems based on forage finishing or grain-forage diets with or without growth promotans: 2. Meat quality, fatty acid composition, and overall palatability. Journal of Animal Science, 86, 1678-1689.

Folch, J., Lees, M., \& Sloane-Stanley, G. H. S. (1957). A simple method for the isolation and purification of total lipids from animal tissues. Journal Biological Chemistry, 226, 497-509.

Food and Agriculture Organization for the United Nations. (2010). Fats and fatty acids in Human Nutrition: Report of an expert consultation, FAO Food and Nutrition, 91.

Garcia, P. T., \& Casal, J. J. (2012). Linoleic and alfa-linolenic acids content of pork, beef and lamb lipids. In I. Onakpoya, \& Nova. (Eds.), Linoleic acid: Sources, Biochemical Properties and Health Effects. Science Publishers.

Garcia, P. T., Pensel, N. A., Sancho, A. M., Latimori, N. J ., Kloster, A. M., Amigone, M. A., \& Casal, J. J. (2008). Beef lipids in relation to animal breed and nutrition in Argentina. Meat Science, 79, 500-508.

Herdmann, A., Martin, J., Nuernberg, G., Wegner, J., Dannenberger, D., \& Nuernberg, K (2010) How do n-3 fatty acid (short-time restricted vs. unrestricted) and n-6 fatty acid enriched diets affect the fatty acid profile in different tissues of German Simmental bulls? Meat Science, 86, 712-719.

Howe, P., Meyer, B., Record, S., \& Baghurst, K. (2006). Dietary intake of long-chain omega 3 polyunsaturated fatty acids: Contribution of meat sources. Nutrition, 22, 47-53.

Humada, M. L., Serrano, E., Sañudo, C., Rolland, D. C., \& Dugan, M. E. R. (2012). Production system and slaughter age effects on intramuscular fatty acids from Young Tudanca bulls. Meat Science, 90, 678-685. 
Lee, M. R. F., Evans, P. R., Nute, G. R., Richardson, R. I., \& Scollan, N. D. (2009). A comparison between red clover silage and grass silage feeding on fatty acid composition, meat stability and sensory quality of the M. Longissimus muscle of dairy cull cows. Meat Science, 81, 738-744.

Leheska, J. M., Thompson, L. D., Howe, J. C., Hentges, E., Boyce, J., Brooks, J. C., ... Miller, M. F. (2008). Effects of conventional and grass-feeding systems on the nutrient composition of beef. Journal of Animal Science, 86, 3575-3585.

Malau-Aduli, A. E. O., Siebert, B. D., Bottema, C. D. K., \& Pitchford, W. S. (1998). Breed comparison of the fatty acids composition of muscle phospholipids in Jersey and Limousin cattle. Journal of Animal Science, 76, 766-773.

Muchenje, V., Hugo, A., Dzama, K., Chimonyo, M., Strydom, P. E., \& Raats, J. G. (2009). Cholesterol levels and fatty acid profiles of beef from three cattle breeds raised on natural pasture. Journal of Food Composition and Analysis, 22, 354-358.

Nuernberg, K., Dannenberger, D., Nuernberg, G., Ende, K., Voigt, J., Scollan, N. D., ... Richardson, R. I. (2005). Effect of grass-based and a concentrate feeding system on meat quality characteristics and fatty acid composition of Longissimus muscle in different cattle breeds. Livestock Production Science, 94, 137-147.

Pariza, M. W., Park, Y., \& Cook, M. E. (2001). The biologically active isomers of conjugated linoleic acid. Progress of Lipid Research.

Sarries, M. V., Murray, B. E., Moloney, A. P., Troy, D., \& Berian, M. J. (2009). Effect of cooking on the fatty acid composition of Longissimus dorsi muscle from beef steers fed rations designed to increase the concentration of conjugated linoleic acid in tissue. Meat Science, 81, 307-312.

Scollan, J. P., Hocquette, L. P., Nuernberg, K., Dannenberger, D., Richardson, I., \& Moloney, A. (2006). Innovation in beef production systems that enhance the nutritional and health value of beef lipids and their relationship with meat quality. Meat Science, 74, 17-33.

Sexton, A. K., Krehbiel, C. R., Dillwith, J. W., Madden, R. D., Mc Murphy, C. P., Lalman, D. L., \& Mateescu, R. G. (2012). Effect of muscle type, sire breed, and time of weaning on fatty acid composition of finishing steers. Journal of Animal Science, 90, 616-625.

Smink, W., Vestegen, M. W., \& Gerritz, W. J. (2013). Effect of intake of linoleic acid and alfa-linolenic acid levels on conversion into long-chain polyunsaturated fatty acids in back fat and in intramuscular fat of growing pigs. Journal Animal Physiology and Animal Nutrition, 97, 558-565.

Van Elswyk, M. E., \& McNeill, S. H. (2014). Impact of grass/forage feeding versus grain finishing on beef nutrients and sensory quality: The U.S. experience. Meat Science, 96, 535-540.

Varela, A., Oliete, B., Moreno, T., Portela, C., Monserrat, L., Caballo, J., \& Sanchez, L. (2004). Effect of pasture finishing on the meat characteristics and intramuscular fatty acid profile of steers of the Rubia Gallega breed. Meat Science, 67, 515-522.

Whelan, J. (2008). The health implications of changing linoleic acid intakes. Prostaglandins, Leukotrienes and Essential Fatty Acids, 79, 165-168. 
Williams, C. M. (2000). Dietary fatty acids and human health. Annales de Zootecnie, 49, 165-180. 